\title{
Structural insights into Plasmodium falciparum nicotinamide mononucleotide adenylyltransferase: oligomeric assembly
}

\author{
Luis Ernesto Contreras-Rodríguez, Catherin Yizet Marin-Mogollon*, \\ Lina Marcela Sánchez-Mejía, María Helena Ramírez-Hernández/+ \\ Universidad Nacional de Colombia, Facultad de Ciencias, Laboratorio de Investigaciones Básicas en Bioquímica, Bogotá, Colombia
}

The biochemical pathways involved in nicotinamide adenine dinucleotide (NAD) biosynthesis converge at the enzymatic step catalysed by nicotinamide mononucleotide adenylyltransferase (NMNAT, EC: 2.7.7.1). The majority of NMNATs are assembled into homo-oligomeric states that comprise 2-6 subunits. Recently, the NMNAT of Plasmodium falciparum (PfNMNAT) has been identified as a pharmacological target. The enzymatic characterisation, cellular location, and tertiary structure of the PfNMNAT protein have been reported. Nonetheless, its quaternary structure remains to be explored. The present study describes the oligomeric assembly of the $6 \mathrm{x}$ His-PfNMNAT recombinant protein using immobilised metal affinity chromatography coupled with size exclusion chromatography (SEC) and native protein electrophoresis combined with Ferguson plot graphing. These chromatographic approaches resulted in the elution of an active monomer from the SEC column, whereas the Ferguson plot indicated a dimeric assembly of the $6 \mathrm{x}$ His-PfNMNAT protein.

Key words: NMNAT - oligomers - Plasmodium falciparum

Nicotinamide adenine dinucleotide (NAD) and its phosphorylated form (NADP) are coenzymes involved in REDOX reactions related to energetic metabolism and oxidative stress defence mechanisms. In addition, these molecules are substrates of different enzymes associated with DNA repair and cellular death programs, calcium mobilisation and signalling, genetic expression and circadian rhythm regulation. ${ }^{(1)}$ NAD biosynthesis can be carried out from diverse chemical precursors through the salvage and de novo pathways. These routes merge at the enzymatic step catalysed by nicotinamide mononucleotide adenylyltransferase (NMNAT EC: 2.7 .7 .1$){ }^{(2)}$

Functionally, NMNATs are mononucleotide transferases that synthesise the corresponding dinucleotide from nicotinamide mononucleotide (NMN) or its nicotinic acid derivative $(\mathrm{NaMN})$ and ATP. Even though its existence was first discovered in yeast, there have been multiple studies involving NMNATs from Archaea, Bacteria and Eukarya sources. Some organisms possess multiple isoforms whose subcellular distribution and kinetic parameters are distinct. ${ }^{(3)}$

Multiple X-ray crystallography studies have been carried out to determine the structure of NMNATs from organisms of all three domains of life. These structural analyses have revealed a conserved architecture characterised by the presence of an $\alpha / \beta$ domain, termed the Rossmann

doi: 10.1590/0074-02760180073

Financial support: COLCIENCIAS (project 110156935240).

*Current address: Leiden Malaria Research Group, Department of

Parasitology, Leiden University Medical Center (LUMC), The Netherlands

+ Corresponding author: mhramirezh@unal.edu.co

Received 7 February 2018

Accepted 5 June 2018 fold, which comprises the elements associated with substrate binding and catalysis..$^{(4)}$ Regarding quaternary structure, most NMNATs exhibit homo-oligomeric assemblies composed of 2-6 subunits. NMNATs from Gram-positive bacteria, such as Bacillus anthracis and Staphylococcus aureus, exhibit dimeric associations ${ }^{(5,6)}$, while the NMNAT from $B$. subtilis and human isoform 3 display tetrameric assemblies. ${ }^{(7,8)}$ The most complex organisation has been observed in the NMNAT from Methanococcus jannaschii and human isoform 1, which forms hexameric assemblies. (4) A few NMNATs have been reported to be monomeric, such as the NMNATs from Escherichia coli (NadD), Pseudomonas aeruginosa, and human isoform 2.9-11)

The vital importance of NMNAT in NAD biosynthesis has established this enzyme as a promising therapeutic target for cancer control ${ }^{(12)}$, neurodegenerative disorders ${ }^{(13)}$ and infectious disease treatments. ${ }^{(14,15)}$ In the context of eukaryotic parasites, our research group has identified and characterised NMNATs from Leishmania braziliensis (LbNMNAT) ${ }^{(16)}$, Giardia lamblia (GINMNAT) ${ }^{(17)}$, and Trypanosoma cruzi (TcNMNAT). (18) Concerning the NMNAT from Plasmodium falciparum (PfNMNAT), different functional and structural aspects have been studied. ${ }^{(19,20)}$ However, its quaternary structure has not yet been determined.

This research presents the analysis of the oligomeric state of the $6 \times$ His-PfNMNAT protein through immobilised metal affinity chromatography (IMAC) coupled with size exclusion chromatography (SEC) and native protein electrophoresis (PAGE) combined with Ferguson plot graphing.

Initially, a bioinformatics search in the PlasmoDB database (http://plasmodb.org/plasmo/) permitted the identification of the pfnmnat ORF in the genome of the 3D7 strain. The search was performed with the tBLASTn tool using the consensus sequence of multiple 
previously-characterised NMNATs as query sequences. The identified ORF (PF3D7 1327600) was amplified by polymerase chain reaction (PCR) from $1 \mathrm{mg}$ of $P$. falciparum (FCB2 strain) gDNA, which was extracted with proteinase $\mathrm{K}$ and phenol chloroform according to previously described methodologies. ${ }^{(21)}$ PCR was performed using Platinum Pfx (Invitrogen, Carlsbad, USA) polymerase and the following oligonucleotides: forward 5'-CACCATGCATAAGAATATATGT-3', reverse 5'-CTAATTAAAATCATATAAGTT-3'. The thermal cycles consisted of an initial denaturation at $94^{\circ} \mathrm{C}$ for 2 min, followed by 30 cycles of denaturation at $94^{\circ} \mathrm{C}$ for 15 $\mathrm{s}$, annealing at $55^{\circ} \mathrm{C}$ for $30 \mathrm{~s}$, and extension at $68^{\circ} \mathrm{C}$ for 1 min. Final extension was performed at $68^{\circ} \mathrm{C}$ for $7 \mathrm{~min}$. The pfnmnat fragment was inserted directly into the pET100/D-Topo (Invitrogen, Carlsbad, USA) expression vector. The identity of the pET100-PfNMNAT recombinant vector was verified by DNA sequencing.

Expression of the corresponding $6 \mathrm{x}$ His-PfNMNAT recombinant protein $(\sim 28 \mathrm{kDa})$ was induced in the $E$. coli Codon Plus (DE3) RIL strain. Luria Bertani medium supplemented with ampicillin $(100 \mathrm{mg} / \mathrm{mL})$ and chloramphenicol $(50 \mathrm{mg} / \mathrm{mL})$ was used. Protein expression was induced overnight $(\mathrm{ON})$ at $24^{\circ} \mathrm{C}$ with IPTG $(0.5 \mathrm{mM})$ when an optical density (OD) of 0.7 at $600 \mathrm{~nm}$ was reached. The recombinant protein was fused to an N-terminal $6 \mathrm{x}$
His tag. An IMAC protocol was used employing a nickel nitrilotriacetic acid resin (Ni-NTA) (Qiagen) as follows: induced cells were harvested by centrifugation at 8000 rpm for $15 \mathrm{~min}$ at $4^{\circ} \mathrm{C}$, re-suspended in lysis buffer $(50$ $\mathrm{mM} \mathrm{NaH} \mathrm{PO}_{4}, 200 \mathrm{mM} \mathrm{NaCl}, 10 \mathrm{mM}$ imidazole, $\mathrm{pH}$ 8.0) (5 mL/g wet weight) supplemented with lysozyme (1 mg/ $\mathrm{mL}$ ) and incubated for $30 \mathrm{~min}$ at $4^{\circ} \mathrm{C}$ with shaking. Cells were lysed by maceration on liquid nitrogen and centrifuged at $12000 \mathrm{rpm}$ for $20 \mathrm{~min}$ at $4^{\circ} \mathrm{C}$. The soluble fraction was incubated for $2 \mathrm{~h}$ at $4^{\circ} \mathrm{C}$ with $500 \mathrm{~mL}$ of Ni-NTA resin pre-equilibrated in lysis buffer. The resin was washed with $15 \mathrm{~mL}$ of washing buffer $\left(50 \mathrm{mM} \mathrm{NaH}_{2} \mathrm{PO}_{4}, 200 \mathrm{mM}\right.$ $\mathrm{NaCl}, 30 \mathrm{mM}$ imidazole, $\mathrm{pH} 8.0$ ), and the elution process was carried out with $500 \mathrm{~mL}$ of elution buffer $(50 \mathrm{mM}$ $\mathrm{NaH}_{2} \mathrm{PO}_{4}, 200 \mathrm{mM} \mathrm{NaCl}, 250 \mathrm{mM}$ imidazole, $\mathrm{pH}$ 8.0).

The IMAC 6 x His-PfNMNAT eluates $(500 \mathrm{mg})$ were analysed by SEC in a Superdex 200 10/300 GL column (GE Healthcare Life Sciences) pre-equilibrated in equilibrium buffer ( $50 \mathrm{mM} \mathrm{NaH}_{2} \mathrm{PO}_{4}, 300 \mathrm{mM} \mathrm{NaCl}, 0.5 \mathrm{mM}$ DTT). SEC was carried out in the Äkta Purifier system (GE Healthcare Life Sciences) at $4^{\circ} \mathrm{C}$ with a $0.5 \mathrm{~mL} / \mathrm{min}$ flow rate. Fractions were monitored by absorbance at 280 nm. A molecular weight (MW) calibration curve (partition coefficient $\left(K_{a v}\right)$ vs Log MW) was constructed using standard proteins [lysozyme, carbonic anhydrase, bovine serum albumin (BSA)], and 6 x His-HsNMNAT1. ${ }^{(22)}$
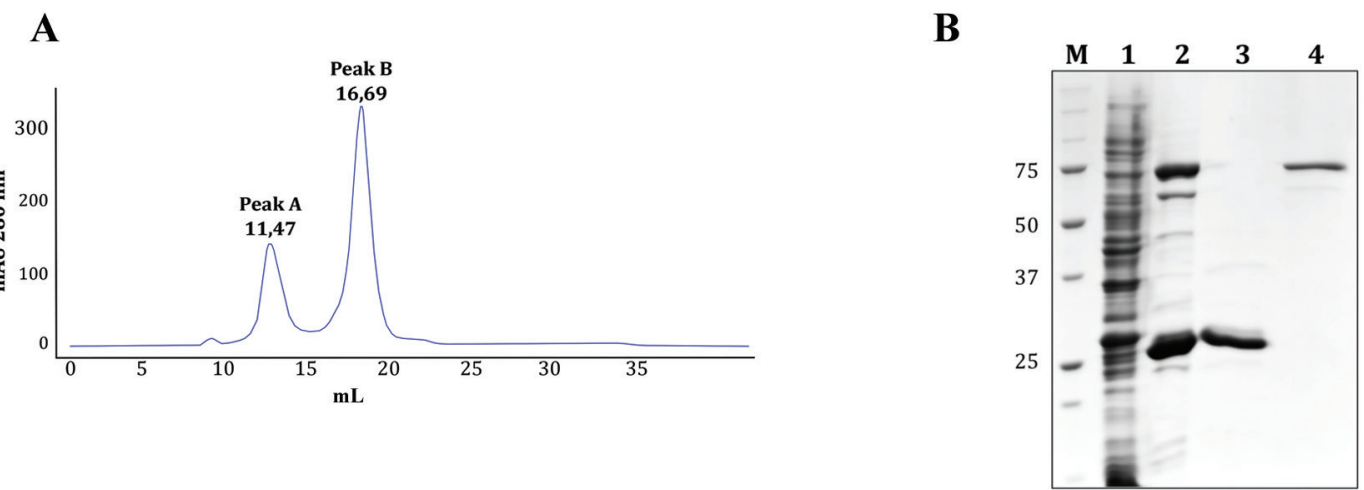

C

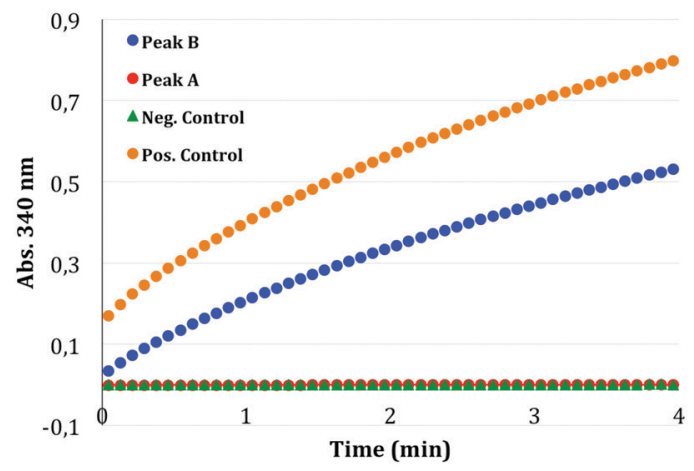

Fig. 1: immobilised metal affinity chromatography coupled with size exclusion chromatography (IMAC-SEC) was used to purify an active $6 \mathrm{x}$ HisPlasmodium falciparum nicotinamide mononucleotide adenylyltransferase (PfNMNAT) recombinant protein. (A) IMAC eluate 1 was subjected to SEC. The corresponding chromatogram shows two main peaks (A-B). (B) Sodium dodecyl sulfate polyacrylamide gel electrophoresis (SDS-PAGE) 12\%T. Coomassie R-250 staining. Lanes: 1. Original soluble fraction; 2. IMAC eluate 1 injected in the SEC column; 3. Peaks B fraction; 4. Peaks A fraction; M. MW (kDa). (C) The enzymatic activity of the $6 \mathrm{x}$ His-PfNMNAT recombinant protein from peak B was verified via coupled enzymatic assays. Negative control: elution buffer. Positive control: 6 x His-Leishmania braziliensis nicotinamide mononucleotide adenylyltransferase (LbNMNAT) recombinant protein. ${ }^{(16)}$ 
The SEC chromatogram showed two peaks (Fig. 1A) whose fractions were analysed by sodium dodecyl sulfate polyacrylamide gel electrophoresis (SDS-PAGE) and coupled enzymatic assays. SDS-PAGE revealed high MW proteins in peak A, while the $6 \mathrm{x}$ His-PfNMNAT recombinant protein was eluted in peak B (Fig. 1B).

Enzymatic assays were performed with this sample, which showed an increase in absorbance at $340 \mathrm{~nm}$ (Fig. 1C). The enzymatic assays were achieved as previously described for other NMNATs. ${ }^{(23)}$ Initially, the following reaction mix was prepared: $40 \mathrm{mM}$ ethanol, $25 \mathrm{mM}$ HEPES/KOH pH 7.4, $10 \mathrm{mM} \mathrm{MgCl}, 1.25 \mathrm{mM}$ ATP (Sigma, St. Louis, USA), 1.25 mM NMN (Sigma), and $2 \mathrm{U}$ ADH (Sigma). The mixture was aliquoted into 96-well plates and the reaction was initiated by adding $2.5 \mathrm{mg}$ of the recombinant protein. The reactions were incubated at $37^{\circ} \mathrm{C}$ for $4 \mathrm{~min}$. NADH synthesis was monitored at $340 \mathrm{~nm}$ in a GENios microplate reader (Teçan, Salzburg, Austria).

The enzymatic activity of the $6 \times$ His-PfNMNAT recombinant protein was confirmed via direct enzymatic assays that measured NAD synthesis from NMN and ATP by reverse phase high-performance liquid chromatography (RP-HPLC) (Fig. 2). These assays were performed using the reaction mixture described above without ethanol and $\mathrm{ADH}$ at $37^{\circ} \mathrm{C}$ for $10 \mathrm{~min}$. The assays were stopped and neutralised with $1.2 \mathrm{M} \mathrm{HClO}_{4}$ and $1 \mathrm{M}$

A

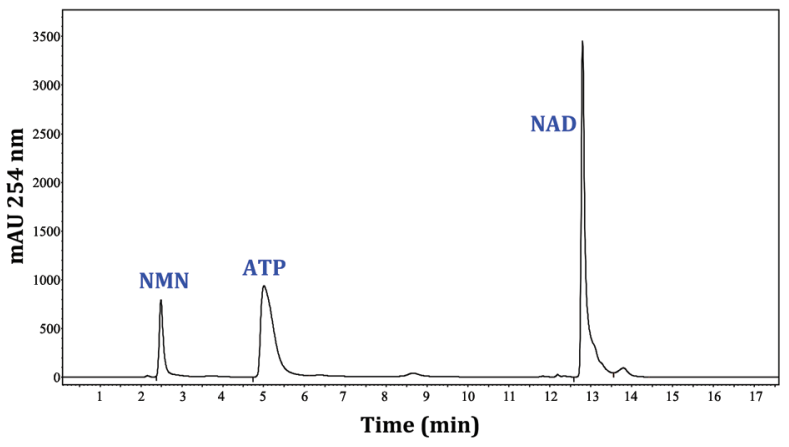

$\mathrm{K}_{2} \mathrm{CO}_{3}$, respectively. ${ }^{(24)}$ The reactions were analysed by RP-HPLC in an Agilent 1200 Series instrument with a C18 column $(25 \mathrm{~cm}$ long x $4.6 \mathrm{~mm}$ inner diameter, $5 \mathrm{~mm}$ particle size, Phenomenex). A step gradient with buffers A $\left(0.1 \mathrm{mM} \mathrm{KH}_{2} \mathrm{PO}_{4}, \mathrm{pH} 6.0\right)$ and $\mathrm{B}\left(0.1 \mathrm{mM} \mathrm{KH}_{2} \mathrm{PO}_{4}\right.$, $\mathrm{pH} 6.0,20 \% \mathrm{v} / \mathrm{v}$ methanol) was applied as follows: $7 \mathrm{~min}$ buffer A (100\%), 2 min buffer B (30\%), 4 min buffer B $(60 \%), 2$ min buffer B (30\%), and 2 min buffer A (100\%). The analysis was performed at room temperature with a $1.5 \mathrm{~mL} / \mathrm{min}$ flow rate and a $20 \mathrm{~mL}$ injection volume per sample. Analytes were detected at $254 \mathrm{~nm}$.

To study the quaternary structure of the $6 \mathrm{x}$ His-PfNMNAT recombinant protein, the putative oligomeric assembly of the $6 \times$ His-PfNMNAT recombinant protein which eluted in peak B (Fig. 1B) was inferred from its MW. To determine its MW, an MW calibration curve was constructed by injecting a mixture of standard proteins onto the SEC column. From the corresponding chromatogram (Fig. 3), the partition coefficient $\left(K_{a v}\right)$ for each standard was determined (Table), and the calibration curve was generated (Fig. 4). The elution volume of the $6 \times$ His-PfNMNAT recombinant protein eluted in peak B $(16.69 \mathrm{~mL})$ and was interpolated from the calibration curve to obtain a value of $36.05 \mathrm{kDa}$. This value is close to the theoretical MW of the monomeric recombinant protein, which is $\sim 28$ $\mathrm{kDa}$. Recently, monomers of the PfNMNAT protein were observed via X-ray crystallography. ${ }^{(20)}$

B

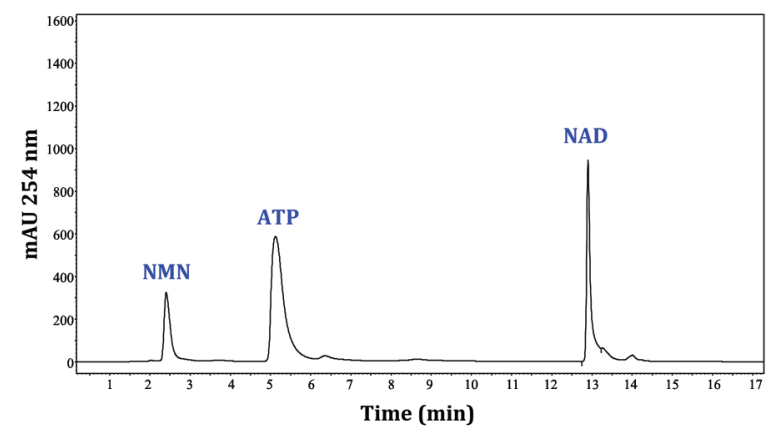

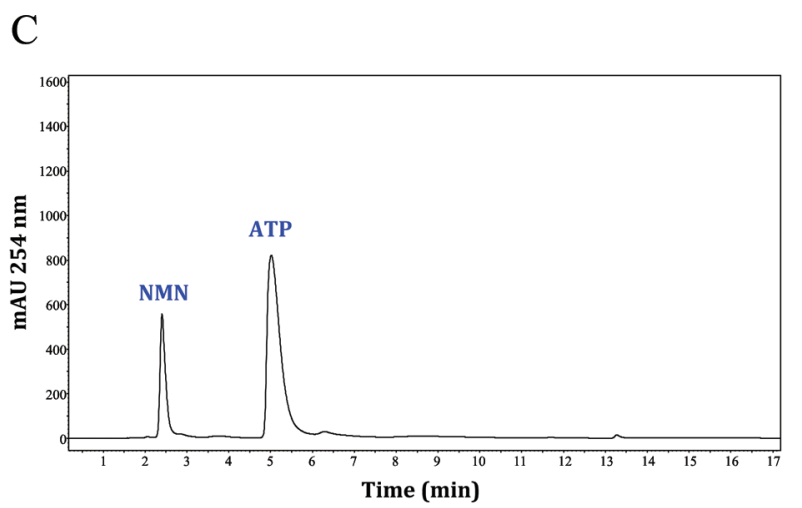

Fig. 2: the purified 6 x His-Plasmodium falciparum nicotinamide mononucleotide adenylyltransferase (PfNMNAT) recombinant protein was catalytically active. The enzymatic activity of the purified protein was corroborated by direct enzymatic assays and reverse phase high-performance liquid chromatography (RP-HPLC). (A) Standard analytes. (B) Analytes from the $6 \mathrm{x}$ His-PfNMNAT reaction. (C) Negative control reaction (without enzyme). 
TABLE

Partition coefficients $\left(K_{a v}\right)$ of the protein standards analysed by size exclusion chromatography (SEC)

\begin{tabular}{lcccc}
\hline Standard & Molecular weight $(\mathrm{MW})(\mathrm{Da})$ & $\mathrm{Log} \mathrm{MW}$ & Elution volume $\left(\mathrm{V}_{\mathrm{e}}\right)(\mathrm{mL})$ & $K_{a v}=\mathrm{V}_{\mathrm{e}}-\mathrm{V}_{\mathrm{o}} / \mathrm{V}_{\mathrm{c}}-\mathrm{V}_{\mathrm{o}}$ \\
\hline 1: 6xHis-HsNMNAT1 (4-mer) & 132000 & 5,12 & 12,27 & 0,26 \\
2: BSA & 66463 & 4,82 & 14,75 & 0,41 \\
3: Carbonic anhydrase & 29000 & 4,46 & 16,85 & 0,55 \\
4: Lysozyme & 14307 & 4,16 & 19,76 & 0,73 \\
\hline
\end{tabular}

Additional data

Dextran blue $\quad$ Void volume $\left(\mathrm{V}_{\mathrm{o}}\right)=8,22 \mathrm{~mL}$

Column: Superdex 200 10/300 GL Column volume $\left(\mathrm{V}_{\mathrm{c}}\right)=24 \mathrm{~mL}$

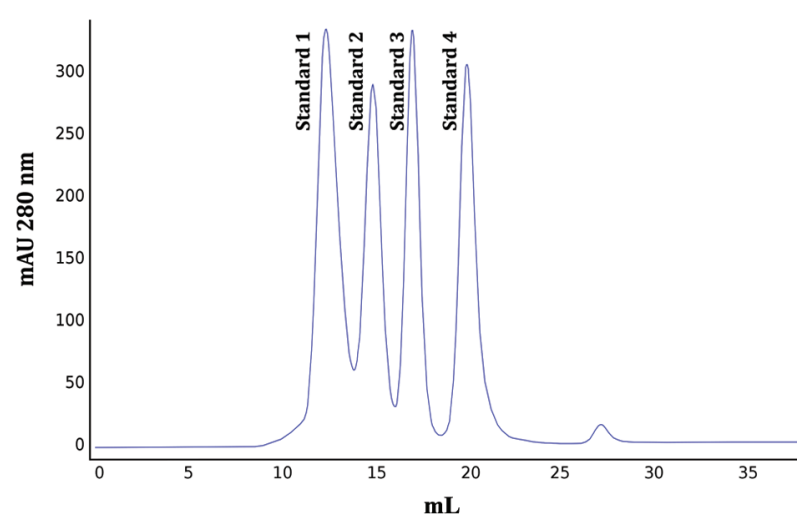

Fig. 3: molecular weight (MW) analysis of protein standards by size exclusion chromatography (SEC). The standardised SEC conditions separated the protein standards referred to in Table.

Our analysis of the quaternary structure of the $6 \mathrm{x}$ His-PfNMNAT recombinant protein by IMAC-SEC revealed that the protein exists in a monomeric and active state. This evidence agrees with previous observations for NMNATs from E. coli (NadD) and P. aeruginosa, whose monomeric states are capable of NAD synthesis. $(9,10)$ Thus, it is reasonable to conclude that the quaternary structure is not a necessary requirement for NMNATs to be active, according to previous observations. ${ }^{(4)}$ The SEC assay was completed in the absence of any substrate or cofactor. Consequently, it would be interesting to evaluate the effect of these molecules on the oligomeric assembly of the $6 \mathrm{x}$ His-PfNMNAT recombinant protein. Other studies have confirmed certain effects: via X-ray crystallography, dimers and tetramers of the NMNAT from $P$. aeruginosa have been observed in the presence of ATP and NaMN, respectively. ${ }^{(10)}$ Furthermore, the NMNAT from $B$. subtilis forms a tetramer in the absence of substrates and a dimer in the presence of one of its products (nicotinic acid adenine dinucleotide, NAAD). ${ }^{(7)}$

To acquire additional information on the quaternary structure of the $6 \mathrm{x}$ His-PfNMNAT recombinant protein by means of complementary techniques, analysis by PAGE and Ferguson plot graphing was performed. Briefly, the IMAC 6 x His-PfNMNAT eluates $(20 \mathrm{mg})$

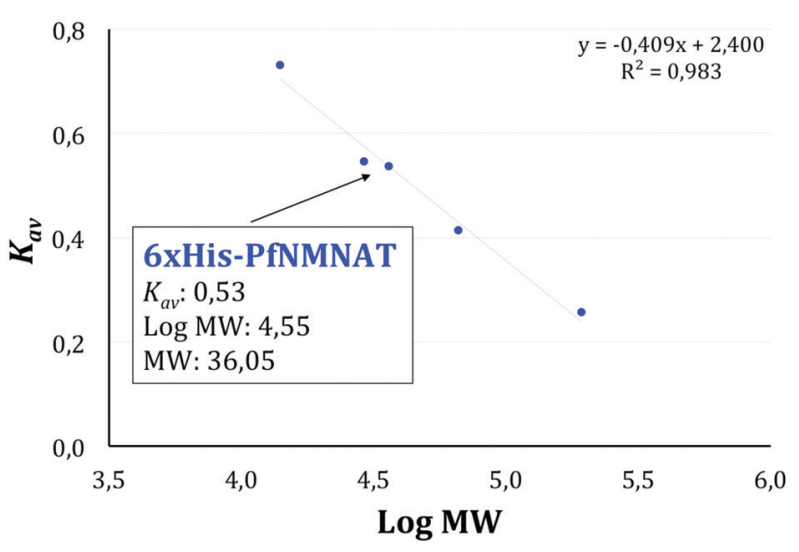

Fig. 4: the 6 x His-Plasmodium falciparum nicotinamide mononucleotide adenylyltransferase (PfNMNAT) recombinant protein eluted as a monomer from the size exclusion chromatography (SEC) column. Molecular weight (MW) calibration curve. The equation of the curve and the $K_{a v}$ value were used to calculate the MW of the 6 x His-PfNMNAT recombinant protein.

were analysed by PAGE, similar to that indicated in Fig. $5 \mathrm{~A}$. The following standard proteins $(40 \mathrm{mg})$ were loaded: lactalbumin, trypsin inhibitor, carbonic anhydrase, ovalbumin and BSA. Four parallel gels, each with a specific acrylamide/bis-acrylamide concentration $(\% \mathrm{~T})(6$, $8,10,12)$, were run, and the relative mobility $\left(R_{f}\right)$ was measured for each sample. Retardation coefficients $\left(K_{r}\right)$ were calculated from the slope of a $\log R_{f}$ vs \% graph (Fig. 5B), and the Ferguson plot was constructed (-Log $K_{r}$ vs Log MW; Fig. 5C). In parallel, the $K_{r}$ of the intense band corresponding to the $6 \times$ His-PfNMNAT recombinant protein (Fig. 5A, lane 6) was interpolated in the Ferguson plot. An MW value of $54.5 \mathrm{kDa}$ was obtained. This result is in concordance with a dimeric assembly of the 6 x His-PfNMNAT recombinant protein. Similar results (dimeric assemblies) have been reported for NMNATs from $B$. anthracis and $S$. aureus. ${ }^{(5,6)}$.

In contrast to the IMAC-SEC experiment, the Ferguson plot indicated that the $6 \mathrm{x}$ His-PfNMNAT recombinant protein formed a dimeric assembly. In agreement with this result, NMNATs with an observed quaternary 
A

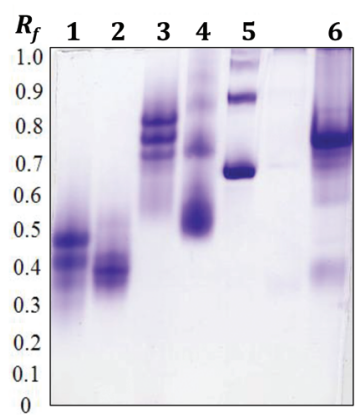

B

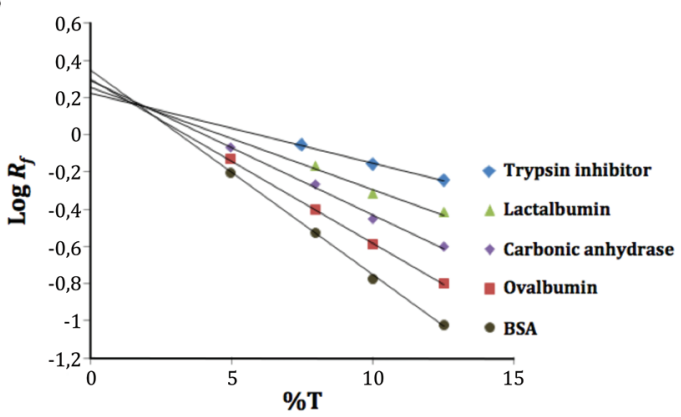

$\mathrm{C}$

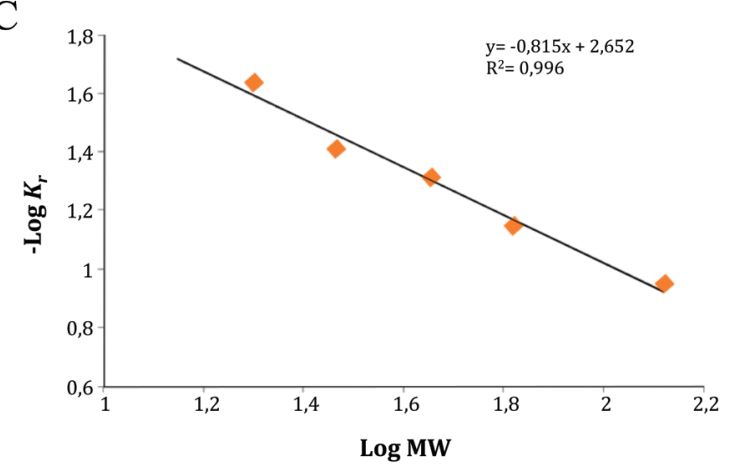

Fig. 5: native protein electrophoresis (PAGE) and Ferguson plot analysis of the protein standards and the $6 \times$ His-Plasmodium falciparum nicotinamide mononucleotide adenylyltransferase (PfNMNAT) recombinant protein. (A) native protein electrophoresis (PAGE) $10 \% \mathrm{~T}$. Coomassie R-250 staining. Lanes: 1. Lactalbumin (14 kDa); 2. Trypsin inhibitor $(20 \mathrm{kDa}) ; 3$. Carbonic anhydrase $(29 \mathrm{kDa}) ; 4$. Ovalbumin $(45$ $\mathrm{kDa})$; 5. BSA (66 kDa); $6.6 \times$ His-PfNMNAT. (B) $\% \mathrm{~T}$ effect on the relative mobility $\left(R_{f}\right)$ of the standards proteins. (C) Ferguson plot. The -Log of the slopes from figure in panel B (retardation coefficients, $K_{r}$ ) is plotted as a function of the $\log$ molecular weight (MW) of the corresponding standards.

structure were characterised by the presence of a structural element implicated in the interaction of subunits. ${ }^{(4)}$ This element comprises a long loop or a loop and a small $\beta$ strand that connects the Rossmann fold to the C-terminal domain. Analysis of the recently-resolved PfNMNAT protein structure ${ }^{(20)}$ revealed that this structural element occurs in the PfNMNAT protein structure (Fig. 6D). Taken together, these observations reinforce our finding and highlight the potential for the PfNMNAT protein to establish oligomeric assemblies.

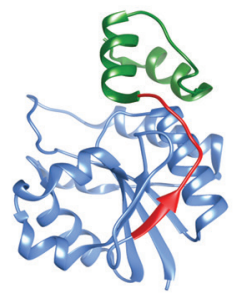

MjNMNAT (1F9A)

A

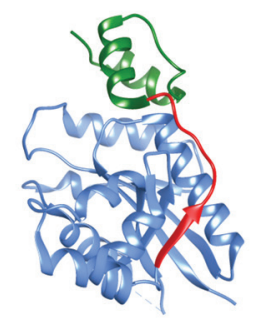

HsNMNAT3 (1NUR)

C

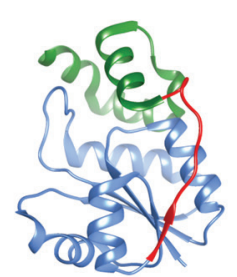

SaNaMNAT (2H29)

B

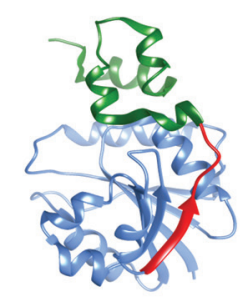

PfNMNAT (5LLT)
D

Fig. 6: the Plasmodium falciparum nicotinamide mononucleotide adenylyltransferase (PfNMNAT) protein possesses the structural elements involved in oligomeric assembly. The quaternary structures of NMNATs exhibit a common structural element (red) between the Rossmann fold (blue) and the C-terminal domain (green). (A-D) NMNAT structures solved by X-ray crystallography. MjNMNAT, SaNaMNAT, HsNMNAT3, PfNMNAT: NMNATs from Methanococcus jannaschii, Staphylococcus aureus, Homo sapiens and Plasmodium falciparum, respectively. The image design was adapted from. ${ }^{(4)}$ Protein Data Bank (PDB) codes are indicated in parentheses. The image was generated with UCSF Chimera. ${ }^{(29)}$

The differences among the results derived from the IMAC-SEC experiment and the Ferguson plot, could be attributed to the specific properties of these techniques, such as the buffer systems, matrices (Sephadex vs polyacrylamide) and the experimental principles (filtration vs electrophoresis). In accordance with this notion, it has been reported that the endogenous and recombinant HsNMNAT1 protein behaves as a tetramer in SEC assays. (25,26) However, independent X-ray crystallography studies of this protein indicated a hexameric assembly. ${ }^{(27,28)}$ The identification of different oligomeric assemblies by the same NMNAT could be related to regulatory mechanisms, which are activated under certain biological conditions.

\section{ACKNOWLEDGEMENTS}

To Mathias Ziegler, University of Bergen (advisor of SEC experiments), and to the Universidad Nacional de Colombia (División de Investigación, Sede Bogotá - DIB).

\section{AUTHORS' CONTRIBUTION}

LE, CY and LM performed experiments; LE and MH designed the study, analysed the data and wrote the paper.

\section{REFERENCES}

1. Nikiforov A, Kulikova V, Ziegler M. The human NAD metabolome: functions, metabolism and compartmentalization. Crit Rev Biochem Mol Biol. 2015; 50(4): 284-97. 
2. Dolle C, Skoge RH, Vanlinden MR, Ziegler M. NAD biosynthesis in humans-enzymes, metabolites and therapeutic aspects. Curr Top Med Chem. 2013; 13(23): 2907-17.

3. Lau C, Niere $M$, Ziegler M. The NMN/NaMN adenylyltransferase (NMNAT) protein family. Front Biosci. 2009; 14: 410-31.

4. Zhai RG, Rizzi M, Garavaglia S. Nicotinamide/nicotinic acid mononucleotide adenylyltransferase, new insights into an ancient enzyme. Cell Mol Life Sci. 2009; 66(17): 2805-18.

5. Sershon VC, Santarsiero BD, Mesecar AD. Kinetic and X-ray structural evidence for negative cooperativity in substrate binding to nicotinate mononucleotide adenylyltransferase (NMAT) from Bacillus anthracis. J Mol Biol. 2009; 385(3): 867-88.

6. Han S, Forman MD, Loulakis P, Rosner MH, Xie Z, Wang H, et al. Crystal structure of nicotinic acid mononucleotide adenylyltransferase from Staphyloccocus aureus: structural basis for NaAD interaction in functional dimer. J Mol Biol. 2006; 360(4): 814-25.

7. Olland AM, Underwood KW, Czerwinski RM, Lo M-C, Aulabaugh A, Bard J, et al. Identification, characterization, and crystal structure of Bacillus subtilis nicotinic acid mononucleotide adenylyltransferase. J Biol Chem. 2002; 277(5): 3698-07.

8. Zhang X, Kurnasov OV, Karthikeyan S, Grishin NV, Osterman AL, Zhang H. Structural characterization of a human cytosolic $\mathrm{NMN} / \mathrm{NaMN}$ adenylyltransferase and implication in human NAD biosynthesis. J Biol Chem. 2003; 278(15): 13503-11.

9. Zhang, Zhou T, Kurnasov O, Cheek S, Grishin NV, Osterman AL. Crystal structures of E. coli nicotinate mononucleotide adenylyltransferase and its complex with deamido-NAD. Structure. 2002; 10(1): 69-79.

10. Yoon H-J, Kim HL, Mikami B, Suh SW. Crystal structure of nicotinic acid mononucleotide adenylyltransferase from Pseudomonas aeruginosa in its apo and substrate-complexed forms reveals a fully open conformation. J Mol Biol. 2005; 351(2): 258-65.

11. Raffaelli N, Sorci L, Amici A, Emanuelli M, Mazzola F, Magni G. Identification of a novel human nicotinamide mononucleotide adenylyltransferase. Biochem Biophys Res Commun. 2002; 297(4): 835-40.

12. Chiarugi A, Dölle C, Felici R, Ziegler M. The NAD metabolomea key determinant of cancer cell biology. Nat Rev Cancer. 2012; 12(11): 741-52.

13. Ruan K, Zhu Y, Li C, Brazill JM, Zhai RG. Alternative splicing of Drosophila Nmnat functions as a switch to enhance neuroprotection under stress. Nat Commun. 2015; 6: 10057.

14. Bi J, Wang H, Xie J. Comparative genomics of NAD(P) biosynthesis and novel antibiotic drug targets. J Cell Physiol. 2011; 226(2): 331-40.

15. Sorci L, Pan Y, Eyobo Y, Rodionova I, Huang N, Kurnasov O, et al. Targeting NAD biosynthesis in bacterial pathogens: structurebased development of inhibitors of nicotinate mononucleotide adenylyltransferase NadD. Chem Biol. 2009; 16(8): 849-61.
16. Contreras LE, Neme R, Ramírez MH. Identification and functional evaluation of Leishmania braziliensis nicotinamide mononucleotide adenylyltransferase. Protein Expr Purif. 2015; 115: 26-33.

17. Forero-Baena N, Sánchez-Lancheros D, Buitrago JC, Bustos V, Ramírez MH. Identification of a nicotinamide/nicotinate mononucleotide adenylyltransferase in Giardia lamblia (GINMNAT). Biochim Open. 2015; 1: 61-9.

18. Niño CH, Forero-Baena N, Contreras LE, Sánchez-Lancheros D, Figarella K, Ramírez MH. Identification of the nicotinamide mononucleotide adenylyltransferase of Trypanosoma cruzi. Mem Inst Oswaldo Cruz. 2015; 110(7): 890-7.

19. O’Hara JK, Kerwin LJ, Cobbold S, Tai J, Bedell T, Reider PJ, et al. Targeting NAD + metabolism in the human malaria parasite Plasmodium falciparum. PLoS One. 2014; 9(4): e94061.

20. Bathke J, Fritz-Wolf K, Brandstädter C, Burkhardt A, Jortzik E, Rahlfs S, et al. Structural and functional characterization of Plasmodium falciparum nicotinic acid mononucleotide adenylyltransferase. J Mol Biol. 2016; 428(24 Pt B): 4946-61.

21. Guerra ÁP, Calvo EP, Wasserman M, Chaparro-Olaya J. Production of recombinant proteins from Plasmodium falciparum in Escherichia coli. Biomedica. 2016; 36(1): 97-108.

22. Berger F, Lau C, Dahlmann M, Ziegler M. Subcellular compartmentation and differential catalytic properties of the three human nicotinamide mononucleotide adenylyltransferase isoforms. J Biol Chem. 2005; 280(43): 36334-41.

23. Balducci E, Emanuelli M, Raffaelli N, Ruggieri S, Amici A, Magni $\mathrm{G}$, et al. Assay methods for nicotinamide mononucleotide adenylyltransferase of wide applicability. Anal Biochem. 1995; 228(1): 64-8.

24. Emanuelli M, Raffaelli N, Amici A, Fanelli M, Ruggieri S, Magni G. Three-minute high-performance liquid chromatographic assay for NMN adenylyltransferase using a 20-mm-long reversed-phase column. J Chromatogr B Biomed Appl. 1996; 676(1): 13-8.

25. Emanuelli M, Natalini P, Raffaelli N, Ruggieri S, Vita A, Magni G. NAD biosynthesis in human placenta: purification and characterization of homogeneous NMN adenylyltransferase. Arch Biochem Biophys. 1992; 298(1): 29-34.

26. Emanuelli M, Carnevali F, Saccucci F, Pierella F, Amici A, Raffaelli N, et al. Molecular cloning, chromosomal localization, tissue mRNA levels, bacterial expression, and enzymatic properties of human NMN adenylyltransferase. J Biol Chem. 2001; 276(1): 406-12.

27. Werner E, Ziegler M, Lerner F, Schweiger M, Heinemann U. Crystal structure of human nicotinamide mononucleotide adenylyltransferase in complex with NMN. FEBS Lett. 2002; 516(1-3): 239-44.

28. Zhou T, Kurnasov O, Tomchick DR, Binns DD, Grishin NV, Marquez VE, et al. Structure of human nicotinamide/nicotinic acid mononucleotide adenylyltransferase. J Biol Chem. 2002; 277(15): 13148-54.

29. Pettersen EF, Goddard TD, Huang CC, Couch GS, Greenblatt DM, Meng EC, et al. UCSF Chimera-a visualization system for exploratory research and analysis. J Comput Chem. 2004; 25(13): 1605-12. 


\section{ERRATUM}

In the article "Structural insights into Plasmodium falciparum nicotinamide mononucleotide adenylyltransferase: oligomeric assembly", DOI number: 10.1590/0074-02760180073, published in Mem Inst Oswaldo Cruz, Rio de Janeiro, Vol. 113(9): e180073, 2018, on page 1:

Where it reads:

ORIGINAL ARTICLE

\section{It should read:}

SHORT COMMUNICATION 